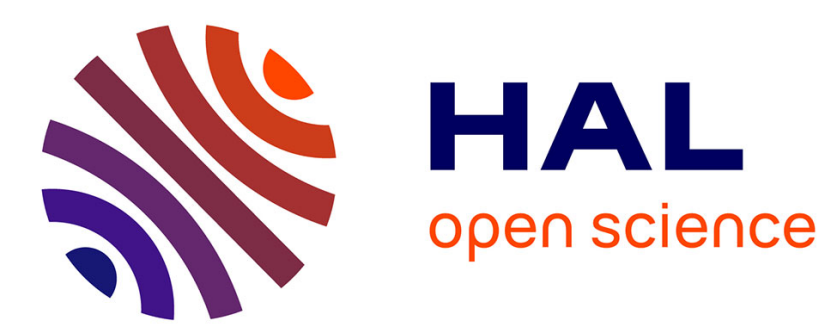

\title{
A probable earthquake scenario near Istanbul determined from dynamic simulations
}

Hideo Aochi, Thomas Ulrich

\section{To cite this version:}

Hideo Aochi, Thomas Ulrich. A probable earthquake scenario near Istanbul determined from dynamic simulations. Bulletin of the Seismological Society of America, 2015, 105 (3), pp.1468-1475. 10.1785/0120140283 . hal-01176838

\section{HAL Id: hal-01176838 https://hal-brgm.archives-ouvertes.fr/hal-01176838}

Submitted on 16 Jul 2015

HAL is a multi-disciplinary open access archive for the deposit and dissemination of scientific research documents, whether they are published or not. The documents may come from teaching and research institutions in France or abroad, or from public or private research centers.
L'archive ouverte pluridisciplinaire $\mathbf{H A L}$, est destinée au dépôt et à la diffusion de documents scientifiques de niveau recherche, publiés ou non, émanant des établissements d'enseignement et de recherche français ou étrangers, des laboratoires publics ou privés. 


\title{
A Probable Earthquake Scenario near Istanbul Determined from Dynamic Simulations
}

\author{
by Hideo Aochi and Thomas Ulrich*
}

\begin{abstract}
We perform numerical simulations of dynamic rupture processes along the North Anatolian fault in the Sea of Marmara, which poses a high risk to the nearby city of Istanbul. Several fault geometry models, nucleation points, and initial stress states are tested. The likelihood of each earthquake scenario is evaluated, and a probabilistic assessment of the ground-motion estimation is proposed. The simulation results suggest that the fault geometrical configuration is not favorable for producing an earthquake of magnitude $6-7$, as no scenario is found. On the contrary, the probability of occurrence of an earthquake of magnitude greater than 7 is high. Most of these large events are characterized by epicenters located in the central or eastern parts of the Sea of Marmara. However, the possibility of a western-initiated rupture propagating eastward, the worst scenario for the Istanbul region, cannot be ruled out. Many simulations led to supershear ruptures, as observed for the nearby 1999 İzmit earthquake, and this significantly influences ground-motion prediction in the region.
\end{abstract}

\section{Introduction}

Istanbul and its surrounding area present one of the highest seismic potentials of the whole Euro-Mediterranean zone for the near future, as well as the attendant risks (e.g., Parsons et al., 2000; SHARE website, see Data and Resources). A large earthquake such as the 1999 İzmit and Düzce earthquakes is expected along the major North Anatolian fault, which runs over $1000 \mathrm{~km}$ across Turkey. The portion beneath the Sea of Marmara remains a seismic gap, silent since the eighteenth century (e.g., Barka et al., 2002), and thus the regional hazard assessments and risk prevention plans are major concerns. An unresolved but fundamental scientific problem concerns the nature of the earthquake scenario to consider. In the current hazard assessment plans, various earthquake scenarios are adopted in a deterministic way (e.g., Erdik et al., 2004; Pulido et al., 2004), but the likelihood of each scenario is never quantitatively assessed. After a few decades of seismological studies on various earthquakes, we know that most earthquake source processes are heterogeneous and complex rather than a simple model with a uniform fault displacement along a fault plane (e.g., Mai and Beroza, 2002). On the other hand, numerical simulations incorporating the mechanics of earthquake rupture (hereafter termed dynamic simulation) revealed that the earthquake rupture, under typical tectonic loading, is controlled by intrinsic features of the fault macroscopic structure (Aochi and Madariaga, 2003; Aochi et al., 2003). In particular, the fault geometry plays a significant role in the

*Now at Department of Earth and Environmental Sciences, Geophysics, Munich University, Theresienstr. 41, 80333 Munich, Germany. earthquake process as inferred from numerical simulations (e.g., Harris and Day, 1999; Aochi et al., 2003; Oglesby et al., 2003; Aochi and Kato, 2010; Kase, 2010; Fukuyama and Hao, 2013; Douilly et al., 2015), as well as from geological observations (e.g., King and Nábĕlek, 1985; Wesnousky, 2008). The aim of this study is to make use of high-performance computing of dynamic simulations to infer the likelihood of several earthquake scenarios in the Sea of Marmara. This information can be particularly relevant for the next generation of quantitative seismic-hazard assessment.

\section{Method}

\section{Geometry Models and Numerical Scheme}

Using well-mapped fault traces under the Sea of Marmara (Le Pichon et al., 2003), we built a 3D model of the North Anatolian fault that assumes a pure strike-slip regime resulting from the rotation of the Marmara and Eurasia blocks (Fig. 1). This model features a complex bending, jog, and bump structure along the strike (LP model). An oversimplified model is also prepared, smoothing out the small geometrical irregularities (SP model). Previously Oglesby and Mai (2012) carried out dynamic rupture simulations on an irregular geometry model consisting of several planar fault segments in this area. Their model is considered to be of intermediate complexity in terms of geometry (OM model). We apply the same simulation procedure as the one used in the simulation of the 1999 İzmit earthquake (Aochi and Madariaga, 2003, hereafter referred as AM03) and assume 


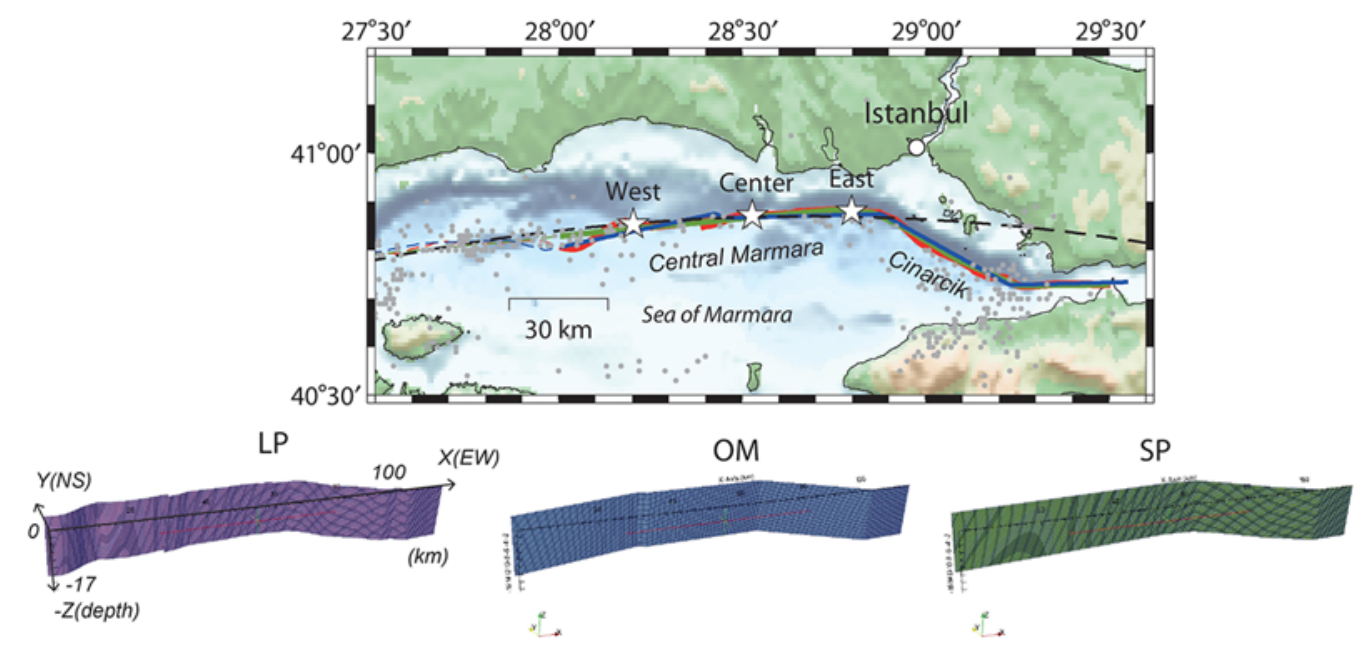

Figure 1. Map of the Marmara region. Three different fault geometry models have been prepared for the purpose of dynamic-rupture simulations, designated LP, SP, and OM. The fault traces are highlighted on the map. The Marmara-Eurasia pole of rotation is indicated by a black dashed curve (Le Pichon et al., 2003). The gray dots show the recent events of magnitude $>3$ extracted from the Kandilli Observatory and Earthquake Research Institute catalog (01 January 2000-14 October 2013). Three different hypocenters (stars) are assumed for each simulation. The simulations are carried out considering only the fault portion drawn with bold lines, which is considered as a seismic gap (e.g., Armijo et al., 2005). The color version of this figure is available only in the electronic edition.

a vertical strike-slip faulting (Le Pichon et al., 2003). The 3D boundary integral equation method (Aochi et al., 2000) allows the complex fault geometry to be dealt with by integrating the rupture criterion on the fault interface. A parameter study is conducted using a relatively coarse resolution of 400 (12,936 elements for the OM model) or $500 \mathrm{~m}$ (8670 and 8330 elements for the LP and SP models, respectively) to cope with the available computing resources (each simulation takes less than $\sim 3 \mathrm{hr}$ on 256 cores). The discretization accuracy has been first verified by conducting a simulation of finer resolution ( $200 \mathrm{~m}$ grid size; i.e., 54,145 elements for the LP model). A mirror source implementation (Quin, 1990) is introduced to simulate strike-slip faulting in a semi-infinite homogeneous elastic medium (e.g., AM03). The $P$ - and $S$-wave velocities are of 6000 and $3464 \mathrm{~m} / \mathrm{s}$, respectively, and the material density is $2700 \mathrm{~kg} / \mathrm{m}^{3}$.

\section{Rupture Criterion and Friction Law}

We use much the same parameter settings as in our previous work on the 1999 İzmit earthquake (AM03), as it was the last large event on the North Anatolian fault, and we poorly know the detailed rupture patterns of the past earthquakes in the Marmara region. The rupture process is formulated by a constitutive relation between the fault slip $\Delta u$ and the shear stress $\tau$, designated as the slip-weakening law:

$$
\tau(\Delta u)=\tau_{\mathrm{r}}+\left(\tau_{\mathrm{p}}-\tau_{\mathrm{r}}\right)\left(1-\Delta u / D_{\mathrm{c}}\right) H\left(1-\Delta u / D_{\mathrm{c}}\right)
$$

(e.g., Ide and Aochi, 2005), in which $H(\cdots)$ is the Heaviside function, $\tau_{\mathrm{p}}$ and $\tau_{\mathrm{r}}$ are peak and residual stresses, and $D_{\mathrm{c}}$ is the critical slip-weakening distance. The two values $\tau_{\mathrm{p}}$ and $\tau_{\mathrm{r}}$ are given by the Coulomb law, depending on the normal stress $\left(\sigma_{\mathrm{n}}\right)$ applied through the static $\left(\mu_{\mathrm{s}}\right)$ and dynamic $\left(\mu_{\mathrm{d}}\right)$ frictional coefficients

$$
\left\{\begin{array}{l}
\tau_{\mathrm{p}}=\sigma_{0}+\mu_{\mathrm{s}} \times \sigma_{\mathrm{n}} \\
\tau_{\mathrm{r}}=\mu_{\mathrm{d}} \times \sigma_{\mathrm{n}}
\end{array},\right.
$$

in which $\sigma_{0}$ is cohesive force and $\sigma_{\mathrm{n}}$ is taken as positive for compression. In this study, we use the same value as AM03, namely, $\mu_{\mathrm{s}}=0.3, \mu_{\mathrm{d}}=0.24, \sigma_{0}=5 \mathrm{MPa}$, and $D_{\mathrm{c}}=80 \mathrm{~cm}$ (at seismogenic zone down to $12 \mathrm{~km}$ of depth), respectively.

We assume the maximum $\left(\sigma_{1}\right)$ and minimum $\left(\sigma_{3}\right)$ principal stresses are oriented horizontally. At each depth, the vertical intermediate stress $\left(\sigma_{2}\right)$ is assigned a value from the hydrostatic pressure (equal to lithostatic pressurehydrostatic pore pressure) (e.g., Sibson, 1982). However, we do not take into account fluid circulation or deformation, so the pore pressure does not play an explicit role in our simulations. The stress field is uniformly loaded on the whole fault system, allowing only changes in the direction of $\sigma_{1}$ and $\sigma_{3}$ (Aochi et al., 2003). For a given direction of $\sigma_{1}$, an optimal fault orientation (angle $\Phi$ ) exists for which the stress state is the closest to the rupture criterion. $\Phi$ is defined as

$$
\Phi=\frac{\pi}{4}-\frac{1}{2} \tan ^{-1} \mu_{\mathrm{s}} .
$$

Designating the normal and shear stresses on this optimal plane as $\sigma_{\mathrm{n}}^{\mathrm{opt}}$ and $\tau^{\mathrm{opt}}$, we define a parameter $T(T \leq 1)$;

$$
T=\left.\frac{\Delta \tau}{\Delta \tau_{\mathrm{b}}}\right|_{\text {for optimal plane }} \equiv \frac{\sigma_{0}+\left(\mu_{\mathrm{s}}-\mu_{\mathrm{d}}\right) \sigma_{\mathrm{n}}^{\mathrm{opt}}}{\tau^{\mathrm{opt}}-\mu_{\mathrm{d}} \sigma_{\mathrm{n}}^{\mathrm{opt}}},
$$

which indicates the ratio of the static stress drop $\Delta \tau$ versus the breakdown strength drop $\Delta \tau_{\mathrm{b}}$. Parameter $T$ is a variable that can be translated into other forms, such as the $S$ parameter on a fault plane of interest $\left[S \equiv\left(\sigma_{0}+\mu_{\mathrm{s}} \sigma_{\mathrm{n}}^{\text {opt }}-\tau^{\text {opt }}\right) /\right.$ $\left.\left(\tau^{\mathrm{opt}}-\mu_{\mathrm{d}} \sigma_{\mathrm{n}}^{\mathrm{opt}}\right)\right]$ in Das and Aki (1977). Note that $S=1 / T-1$ for the optimal plane. $S$ varies with the fault 
(a)

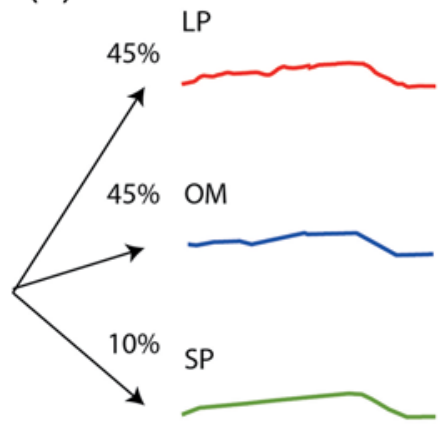

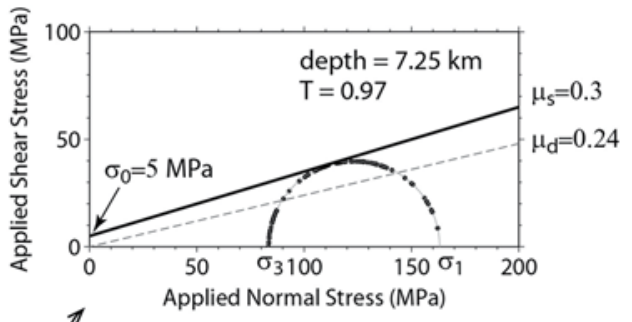

(b)

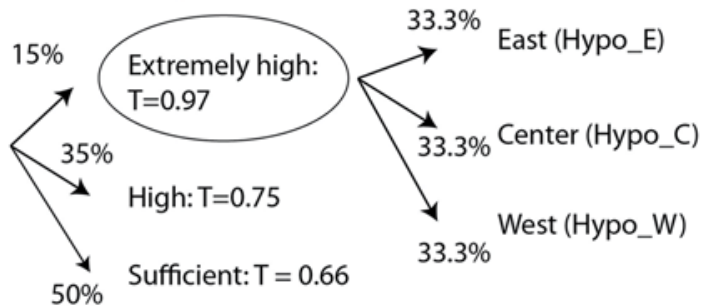

Figure 2. Variable model parameters expressed as a logic tree. This study considers (a) three different fault models, (b) three different stress levels, and (c) three different hypocenter locations. In all, 27 scenarios are calculated. The comparision at the top right shows the MohrCoulomb diagram calculated for $T=0.97$ at a depth of $7.25 \mathrm{~km}$. The black dots represent the applied shear and normal stresses along the fault model LP, the solid line shows the rupture criterion according to the static friction, and the dashed line shows the residual stress level indicated by the dynamic friction (equation 2). The color version of this figure is available only in the electronic edition.

orientation, whereas $T$ is unchanged as it is defined by the external principal stresses. In previous studies of past earthquakes, $T$ ranges from 0.66 to 1.0 (Aochi and Madariaga, 2003; Aochi et al., 2003, 2006). This study supposes three values: $0.66,0.75$, and 0.97 .

The kinetic motion of the North Anatolian fault around the Marmara Sea suggests that the kinematic parameters for the boundary of the Marmara block have a relatively short small circle radius for the pole rotation (e.g., $4.77^{\circ}$ from Le Pichon et al., 2003). This strongly supports the inference of a rotation of $\sigma_{1}$ along the portion of the North Anatolian fault in the Marmara Sea. In this simulation, we assume the optimal stress plane is tangential to the small arc defined by the pole rotation along the fault. The assumption of a uniform level of the stress field along strike is sufficient as a first approximation (Aochi and Madariaga, 2003; Aochi et al., 2003). We set a value of $T$ in each simulation. The stress level applied on the fault varies then spatially. The normal $\left(\sigma_{\mathrm{n}}\right)$ and shear $(\tau)$ stresses applied on any point are functions of the angle between the fault plane and the direction of $\sigma_{1}(\psi)$ :

$$
\left\{\begin{array}{l}
\tau=\Delta \sigma \cos (2 \psi) \\
\sigma_{\mathrm{n}}=\frac{\sigma_{1}+\sigma_{3}}{2}-\Delta \sigma \sin (2 \psi)
\end{array}\right.
$$

in which $\Delta \sigma$ is obtained by the AM03 relationship

$$
\Delta \sigma \equiv \frac{\sigma_{1}-\sigma_{3}}{2}=\frac{\mu_{\mathrm{d}} \sigma_{2}+R\left[\sigma_{0}+\left(\mu_{\mathrm{s}}-\mu_{\mathrm{d}}\right) \sigma_{2}\right]}{\sin 2 \Phi+\mu_{\mathrm{d}} \cos 2 \Phi+R\left(\mu_{\mathrm{s}}-\mu_{\mathrm{d}}\right) \cos 2 \Phi} .
$$

This formulation is applied for all the depths considered to display brittle behavior, namely those from the ground surface down to $12 \mathrm{~km}$. Below $12 \mathrm{~km}$, we consider the fault to be ductile, supposing that the applied stress does not increase anymore and that $D_{\mathrm{c}}$ becomes much longer (AM03). Figure 2 shows an example of the applied shear and normal stresses at a depth of $7.25 \mathrm{~km}$ along the fault system as a Mohr-Coulomb diagram for $T=0.97$. The depth dependency of the confining pressure implies lower stress loading near the ground surface than at depth. It is then expected that coseismic stress perturbations are strong enough at shallow depths to affect the dynamic-rupture process (Aochi et al., 2000).

\section{Parameter Setting in Logic Tree}

Under our current state of knowledge, it is difficult to predict a probable hypocenter location for any earthquake (e.g., Bouchon et al., 2011; Oglesby and Mai, 2012). We accordingly suppose three hypothetical positions along the fault strike (Fig. 1) and assume that an earthquake triggers at a depth of $10 \mathrm{~km}$ (i.e., $2 \mathrm{~km}$ above the base of the seismogenic layer), with an initial crack of $3 \mathrm{~km}$ radius, on which $\tau_{\mathrm{p}}$ is set equal to $\tau_{\mathrm{r}}$. In summary, we considered tens of model parameter sets, which still represent only a portion of all the possibilities that we may or may not be aware of. As shown in Figure 2, we propose here to quantify the likelihood of each simulation by adopting a logic-tree approach (Aochi et al., 2006), which is commonly used in probabilistic risk evaluation (e.g., Sabetta et al., 2005; Field et al., 2009). First, among the three fault geometry models, the models of complex geometry (LP or OM) are more likely than the oversimplified model (SP), because a simple fault model is an approximation on a long wavelength (AM03). A higher weight is then assigned to both LP and OM models. Stress accumulation evolves over time. For the three different accumulation levels of this study (sufficient, high, and extremely high), the first two levels ( $T=0.66$ and 0.75 ) in equation (4) are usually sufficiently high to trigger the characteristic 


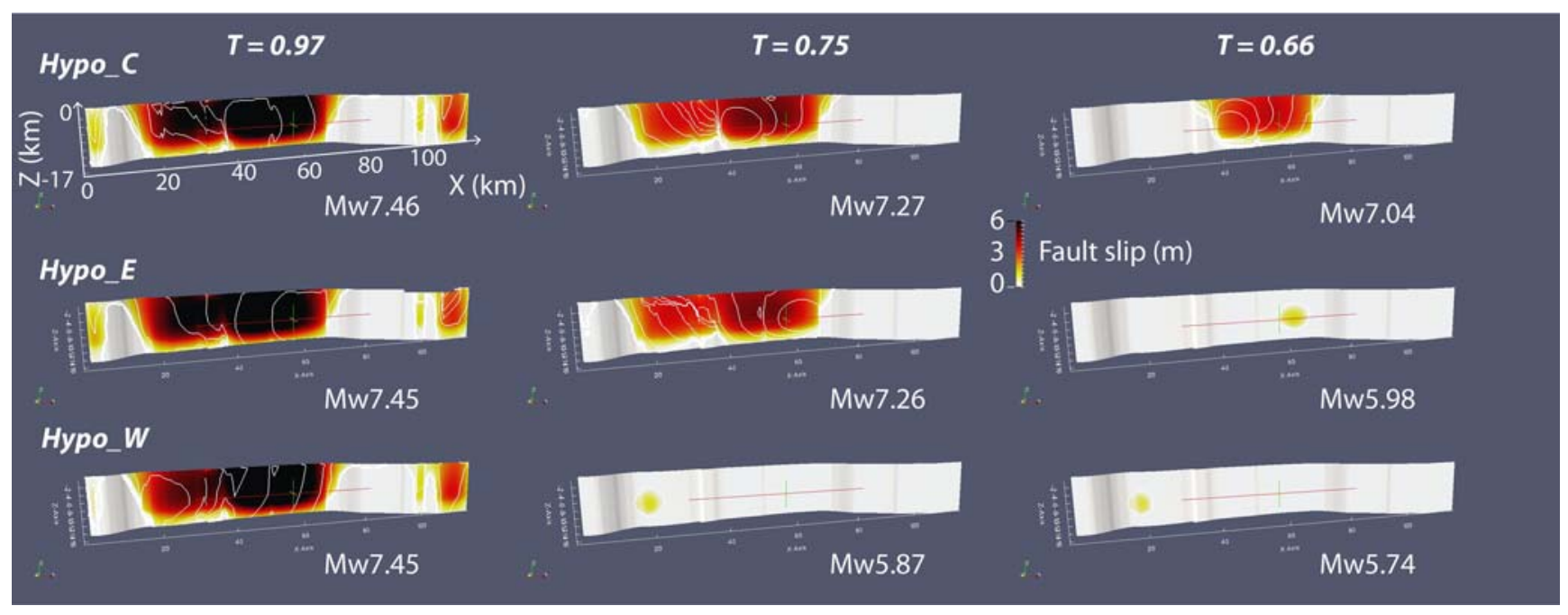

Figure 3. Final slip distribution for the nine simulations based on the LP fault model. The resultant magnitude is shown for each scenario. The rupture front position every $2 \mathrm{~s}$ is made explicit by white lines. From top to bottom, the hypocenter position changes (Hypo_C, center; Hypo_E, east; and Hypo_W, west). From left to right, the stress accumulation level changes $(T=0.97,0.75$, and 0.66 , respectively). The upper left panel shows the spatial scale. The color version of this figure is available only in the electronic edition.

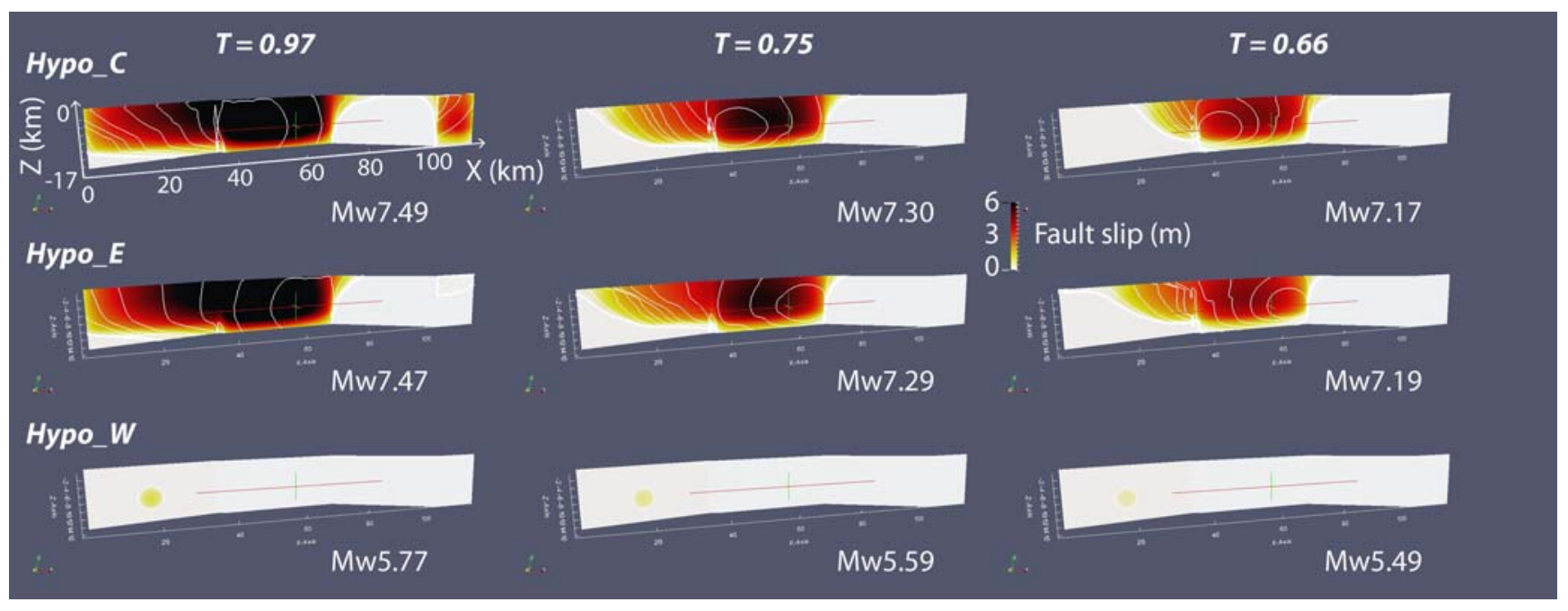

Figure 4. Final slip distribution for the nine simulations based on the OM fault model (see the caption of Fig. 3). The color version of this figure is available only in the electronic edition.

earthquakes in similar situations. The state of extremely high stress accumulation is possible only if the target earthquake has not yet occurred for a long time. However, such an extreme condition is unlikely to occur, as any small perturbation may easily lead to a cascade rupture growth (e.g., Ide and Aochi, 2005). Therefore, the probabilistic weight gets lower as the stress accumulation becomes larger. Finally, we test 27 cases with probabilities ranging from $0.5 \%$ to $7.5 \%$.

\section{Results and Discussion}

All 27 simulation results are presented in Figures 3-5, which correspond to the fault geometry of LP, OM, and SP, respectively. The more detailed Figure A1 shows snapshots of dynamic-rupture simulation corresponding to the cases with (a) the complex (LP) geometry model, (b) $T=0.75$, and (c) the central location of the hypocenter (Hypo_C). A probability of 5.25\% has been assigned, and this case is also represented in the second simulation in the top row of Figure 3. The preferential-ruptured area is controlled by the geometry along the Central Marmara section, because the fault structure is smoother to the east than to the west, and the fault orientation of the eastern part is more optimal to the principal stress field. When the stress level is lower $(T=0.66)$, the rupture propagates only eastward (third simulation in the top row of Fig. 3). In comparison with the other fault models (Figs. 4 and 5) under the same stress condition and with the same hypocenter location, the rupture of the SP model is further extended, and the expected magnitude is consequently greater. In general, the more complex the fault geometry, the greater 


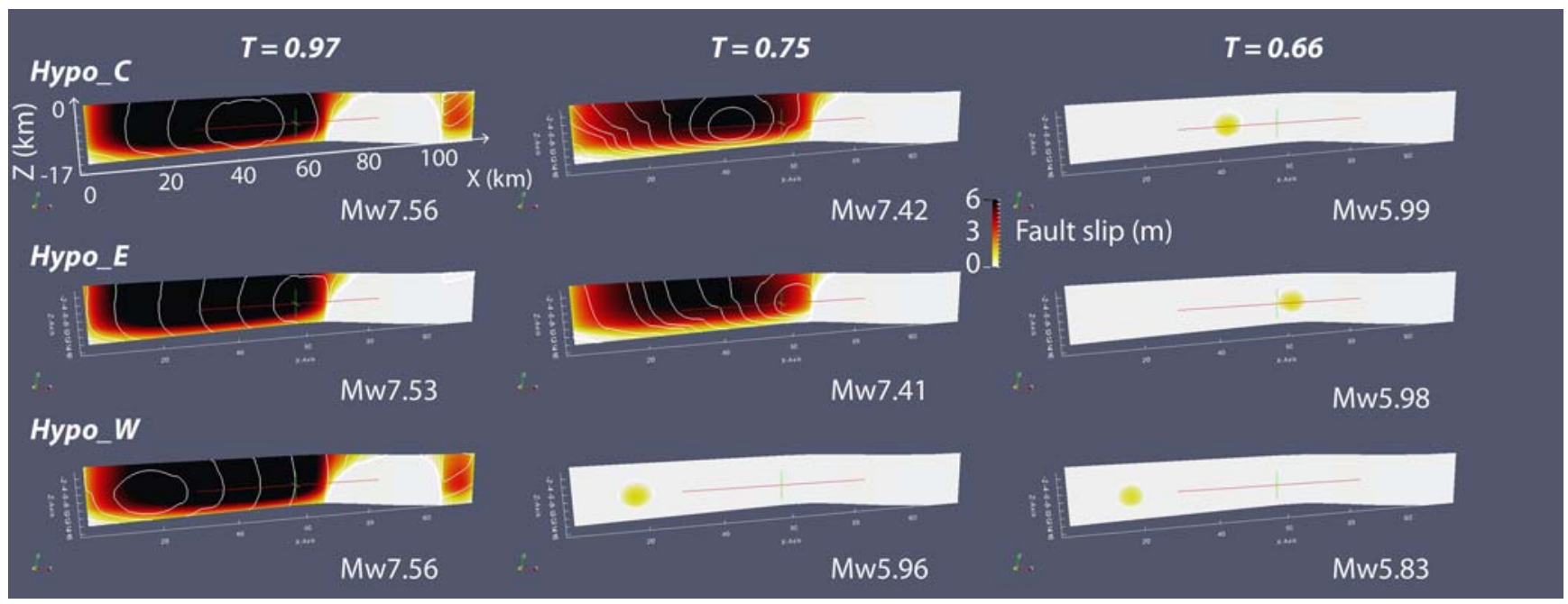

Figure 5. Final slip distribution for the nine simulations based on the SP fault model (see the caption of Fig. 3). The color version of this figure is available only in the electronic edition.

its influence on the rupture process: complex geometry leads to a slow rupture velocity and limits the rupture extent. The hypocenter position also plays a significant role, as previously pointed out (Oglesby and Mai, 2012). All of these variations in rupture scenarios are important for ground-motion prediction.

The east-southeast strike direction of the North Anatolian fault at the eastern part in the Sea of Marmara (the Çınarcık region; Fig. 1) is substantially different from the eastward strike direction of the rest of the fault. None of our scenario earthquakes fully ruptures this section, though ruptures from the west sometimes jump onto the farthest part, where the fault strike becomes again the east-west direction (e.g., the first column in Fig. 3). However, this slip does not contribute significantly to the final magnitude $(<0.1)$. Inversions of the İzmit earthquake suggest that this part of the fault may have ruptured in 1999 (e.g., Bouchon et al., 2011). Thus, this section is ultimately less important for the discussion of the next large earthquake on the North Anatolian in this article.

A statistical analysis of the results, based on the logic-tree approach (Fig. 2), is presented in Figure 6a. First, we find the earthquake scenarios fall into two groups: those of magnitude $<6$ or those of magnitude $>7$. The former group gathers earthquakes that could not propagate much because of the unfavorable stress condition around the supposed hypocenter position. On the other hand, no event achieved a magnitude between 6 and 7. This implies there is no rupture segmentation geometrically controlled at this scale in the case where the earthquake is supposed to start on the Central Marmara section. Finally, a successfully initiated rupture tends to attain a magnitude of 7.3 on average. For the large events, the probability is greater than one half (54\%) for the rupture to start from a centrally located point and propagate bilaterally (Figs. 3-5). The probability is still high (41\%) for the rupture to start from the eastern part and propagate westward. The probability drops to $5 \%$ for a rupture starting from the western extremity and propagating eastward. This low probability reflects the fact that the western part of the fault system is geometrically complex and less favorably oriented within the supposed stress regime.

The 27 cases tested do not cover the entire range of possibilities, and the assigned probabilities remain arbitrary. The uncertainty in the other model parameters fixed in this study $\left(\mu_{\mathrm{s}}, \mu_{\mathrm{d}}, \sigma_{0}\right.$, and $D_{\mathrm{c}}$ in equations 1 and 2) may not be insignificant and could have been taken into account, although they are globally consistent with many other studies presenting dynamic-rupture simulations in which the dynamic stress drop and $D_{\mathrm{c}}$ are of the order of $10 \mathrm{MPa}$ and tenths of centimeters, respectively, for an earthquake of magnitude 7 (e.g., Peyrat et al., 2001; Ruiz and Madariaga, 2013). The proposed scenarios in this study are fully comprehensible from the standpoint of the mechanics and, therefore, appear likely. The spatial heterogeneity introduced in this study originates only from the fault geometry, which principally controls the macroscopic parameters such as the final magnitude and the rupture directivity. Further heterogeneities at smaller scales could be considered (1) deterministically, if we know the spatial distribution of heterogeneity such as fault asperity (Ide and Aochi, 2013), seismic coupling (Schmittbuhl et al., 2014), and other geochemical factors (Tryon et al., 2010), or (2) stochastically, as this is often developed in pseudodynamic modelings (e.g., Mena et al., 2012; Schmedes et al., 2012; Song and Dalguer, 2013; Trugman and Dunham, 2014). Such heterogeneities may make the triggering of multiple fault segments difficult (Kase, 2010). In this meaning, simulations under homogenous conditions give the upper limit of the rupture dimension for each case.

An important feature that is not revealed in the statistics is the potential for supershear rupture (Oglesby and Mai, 2012), that is, when the rupture velocity exceeds the $S$-wave velocity. This occurs on the segments delimited by the supposed hypocenter positions along the Central Marmara section, where the geometry is smooth enough even in the complex model (LP). 

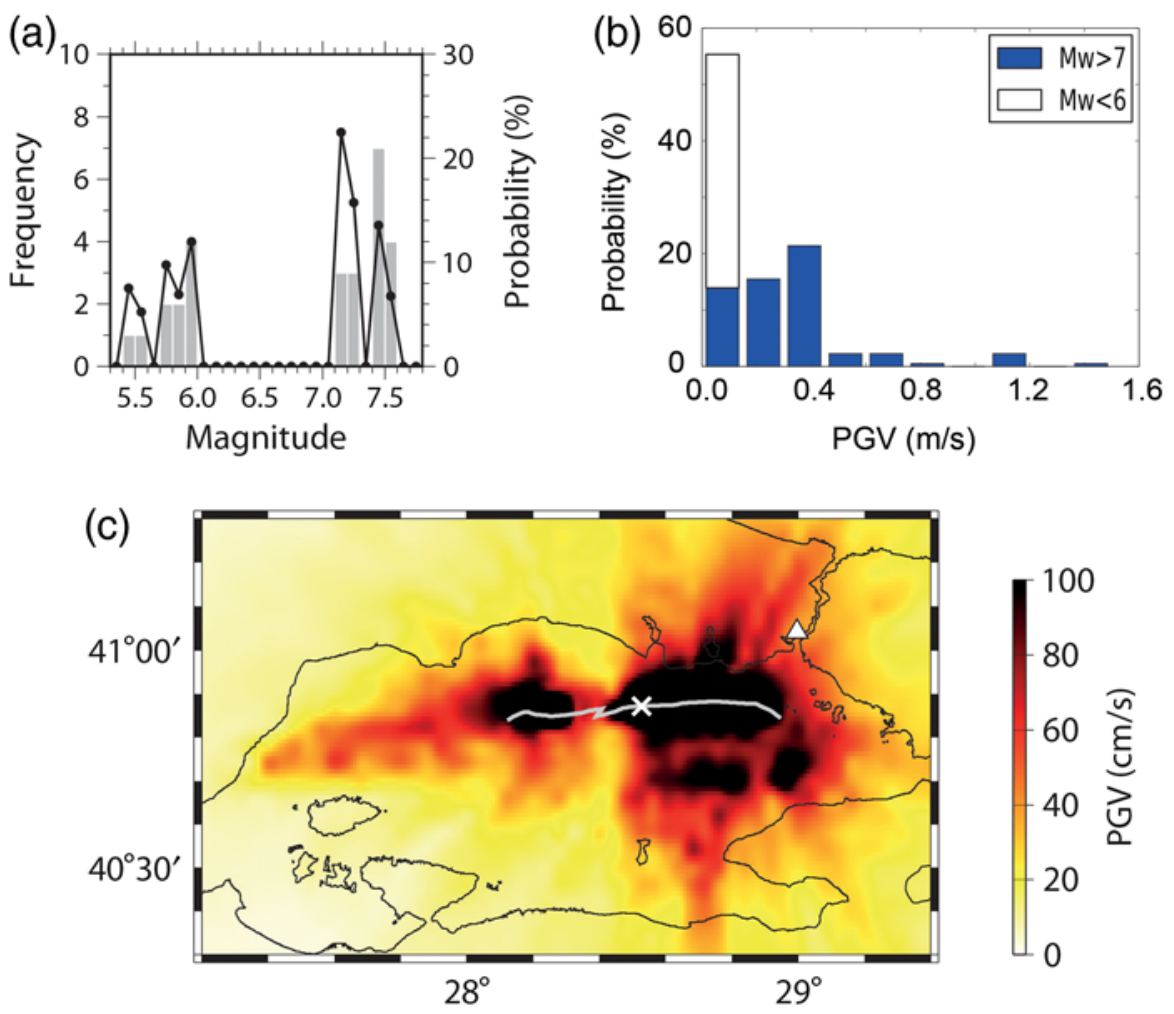

Figure 6. (a) Histogram of the magnitudes $\left(M_{\mathrm{w}}\right)$ obtained in the 27 simulations. The corresponding probabilities are depicted by black lines. (b) Peak ground velocity (PGV) estimation at a point $\left(41.0425^{\circ} \mathrm{N}, 28.9968^{\circ} \mathrm{E}\right.$ ) located in the city center of Istanbul (indicated by a triangle on the map in [c]) from all 27 simulations, classified according to the two magnitude categories. (c) PGV map for the three components (up to $1 \mathrm{~Hz}$ ), calculated through a finite-difference method using a 3D geological model of the region (Aochi and Ulrich, 2014). The source model used here is the case of the complex (LP) fault model, $T=0.75$, and the central location of the hypocenter (Hypo_C), for which snapshots are shown in Figure A1. The ruptured fault traces are shown by the gray lines and the epicenter by a cross. The color version of this figure is available only in the electronic edition.

This occurrence is consistent with the fact that a homogeneous fault allows an important acceleration of the rupture velocity (AM03; Ide and Aochi, 2005). Supershear rupture is also important in terms of seismic-wave radiation. Figure $6 \mathrm{~b}$ characterizes the ground-motion levels provided by all 27 simulations for a grid point $\left(41.0425^{\circ} \mathrm{N}, 28.9968^{\circ} \mathrm{E}\right)$ located in the city center of Istanbul, and Figure 6c shows the peak ground velocity (PGV) map of one scenario, calculated using a finite-difference method in the 3D heterogeneous model (Aochi and Ulrich, 2014). The very strong waves, radiated by a supershear rupture, do not attenuate rapidly with distance (Dunham and Bhat, 2008; Aochi et al., 2011). Supershear ruptures have been observed in several earthquakes, including the 1999 İzmit event (Bouchon et al., 2001); yet their effects on the ground motions have never been considered in seismichazard assessments of this region. The probable groundmotion level due to a large event of magnitude $>7$ is mostly less than $40 \mathrm{~cm} / \mathrm{s}$; yet, a small possibility of extreme ground motion exceeding $1 \mathrm{~m} / \mathrm{s}$ exists.

\section{Conclusion}

In conclusion, combining deterministic simulations of earthquake dynamics with a probabilistic framework makes it possible to quantify probable rupture scenarios for a future earthquake in the target area, the Sea of Marmara, as well as to clarify the mechanical causality of the dynamic system. Our 27 simulated cases in the assumed logic tree, based on the mapped fault traces, produce no events in the magnitude 6-7 range, whereas the probability of occurrence of an earthquake of magnitude $>7$ is high. Epicenters of the large events are more likely in the central and eastern parts of the Sea of Marmara. However, the possibility cannot be ruled out for the rupture to begin in the west and propagate eastward, which constitutes a worst-case scenario for the Istanbul region. Although our model settings do not cover all the possible seismological and geodetical interpretations of the area, the statistical analyses carried out in this study support our mechanical understanding.

For a more reliable hazard evaluation, one will need further parameter investigation-not only on the three variable factors of this study, but also on the other model parameters (heterogeneous stress accumulation, seismic coupling, and fault rheology due to geochemical interaction). Coupling with a geodynamical modeling of interseismic stress accumulation process (e.g., Hergert and Heidbach, 2010) will be a future task as well. On the other hand, a supershear rupture is noticed in many cases of our models, as observed 
during the nearby 1999 İmit earthquake. The simulations suggest taking into account its effect on the ground-motion estimations. The combined dynamic and statistical modeling can improve the current assessment of seismic hazard in the region. One can call on numerical simulations to explore the possible behavior of the fault system for a future earthquake beyond the current empirical approaches.

\section{Data and Resources}

The seismicity and relief data plotted in Figure 1 were provided by Kandilli Observatory and Earthquake Research Institute-National Earthquake Monitoring Center of the Boğaziçi University, Turkey, at http://udim.koeri.boun.edu.tr/ (last accessed September 2014) and by the National Geophysical Data Center (National Oceanic and Atmospheric Administration) at http://www.ngdc.noaa.gov/mgg/global/ global.html (last accessed January 2015), respectively. Seismic Hazard Harmonization in Europe (SHARE) is available at http://dx.doi.org/10.12686/SED-00000001-SHARE. All the other information used in this article came from the published sources listed in the references.

\section{Acknowledgments}

We thank the Kandilli Observatory and the Earthquake Research Institute of the Boğaziçi University, Turkey, for providing their seismic data and for the fruitful discussions. We also thank Julian Lozos and anonymous reviewers for improving our manuscript. This research is a contribution to the European Union's Seventh Programme under the projects REAKT (Grant Number 282862) and MARSite (Grant Number 308417). Most of the numerical simulations were carried out at the French national supercomputing center, Grand Equipement National de Calcul Intensif/Centre Informatique National de l'Enseignement Supérieur (GENCI/CINES), under Grant Number 46700.

\section{References}

Aochi, H., and A. Kato (2010). Dynamic rupture of crosscutting faults: A possible rupture process for the $2007 M_{\mathrm{w}} 6.6$ Niigata-ken Chuetsu-Oki earthquake, J. Geophys. Res. 115, no. B05310, doi: 10.1029/2009JB006556.

Aochi, H., and R. Madariaga (2003). The 1999 Izmit, Turkey, earthquake: Nonplanar fault structure, dynamic rupture process and strong ground motion, Bull. Seismol. Soc. Am. 93, 1249-1266.

Aochi, H., and T. Ulrich (2014). Dynamic rupture and ground motion simulations in the Sea of Marmara, 2nd European Conference of Earthquake Engineering and Seismology (ECEES), Istabul, Turkey, 24-29 August 2014.

Aochi, H., M. Cushing, O. Scotti, and C. Berge-Thierry (2006). Estimating rupture scenario likelihood based on dynamic rupture simulations: The example of the segmented Middle Durance fault, southeastern France, Geophys. J. Int. 165, 436-446.

Aochi, H., V. Durand, and J. Douglas (2011). Influence of super-shear earthquake rupture models on simulated near-source ground motion from the 1999 Izmit, Turkey, earthquake, Bull. Seismol. Soc. Am. 101, 726-741.

Aochi, H., E. Fukuyama, and R. Madariaga (2003). Constraint of fault parameters inferred from nonplanar fault modeling, Geochem. Geophys. Geosyst. 4, no. 2, doi: 10.1029/2001GC000207.

Aochi, H., E. Fukuyama, and M. Matsu'ura (2000). Spontaneous rupture propagation on a non-planar fault in 3D elastic medium, Pure Appl. Geophys. 157, 2003-2027.

Armijo, R., N. Pondard, B. Meyer, G. Uçarkus, B. M. de Lépinay, M.-A. Gustcher, S. Schmidt, C. Beck, N. Çagatay, Z. Çakir, et al. (2005).
Submarine fault scarps in the Sea of Marmara pull-apart (North Anatolian fault): Implication for seismic hazard in Istanbul, Geochem. Geophys. Geosyst. 6, no. 6, doi: 10.1029/2004GC000896.

Barka, A., H. S. Akyüz, G. Sunal, Z. Çakır, A. Dikbaş, B. Yerli, E. Altunel, R. Armijo, B. Meyer, J. B. Chabalier, et al. (2002). The surface rupture and slip distribution of the August 17, 1999 Izmit earthquake (M 7.4), North Anatolian fault, Bull. Seismol. Soc. Am. 92, 43-60.

Bouchon, M., M. P. Bouin, H. Karabulut, M. N. Toksöz, M. Dietrich, and A. J. Rosakis (2001). How fast is rupture during an earthquake? New insights from the 1999 Turkey earthquakes, Geophys. Res. Lett. 28, 2723-2726.

Bouchon, M., H. Karabulut, M. Aktar, S. Özalaybey, J. Schmittbuhl, and M. P. Bouin (2011). Extended nucleation of the $1999 M_{\mathrm{w}} 7.6$ Izmit earthquake, Science 331, 877-880.

Das, S., and K. Aki (1977). A numerical study of two-dimensional spontaneous rupture propagation, Geophys. J. Roy. Astron. Soc. 50, 643-668.

Douilly, R., H. Aochi, E. Calais, and A. M. Freed (2015). Three-dimensional dynamic rupture simulations across interacting faults: The $M_{\mathrm{w}} 7.0$, 2010, Haiti earthquake, J. Geophys. Res., doi: 10.1002/2014JB011595.

Dunham, E., and H. S. Bhat (2008). Attenuation of radiated ground motion and stresses from three-dimensional supershear ruptures, J. Geophys. Res. 113, doi: 10.1029/2007JB005182.

Erdik, M., M. Demircioğlu, K. Sesetyan, E. Durukal, and B. Siyahi (2004). Earthquake hazard in Marmara region, Turkey, Soil Dynam. Earthq. Eng. 24, 605-631.

Field, E. H., T. E. Dawson, K. R. Felzer, A. D. Franel, V. Gupta, T. H. Jordan, T. Parsons, M. D. Petersen, R. S. Stein, R. J. Weldon II, and C. J. Wills (2009). Uniform California Earthquake Rupture Forecast, Version 2 (UCERF 2), Bull. Seismol. Soc. Am. 99, 2053-2107.

Fukuyama, E., and K. X. Hao (2013). Subparallel dipping faults that ruptured during the 2008 Wenchuan earthquake, Bull. Seismol. Soc. Am. 103, 2128-2134.

Harris, R. A., and S. M. Day (1999). Dynamic 3D simulations of earthquakes on en echelon faults, Geophys. Res. Lett. 26, 2089-2092.

Hergert, T., and O. Heidbach (2010). Slip-rate variability and distributed deformation in the Marmara Sea fault system, Nat. Geosci. 3, 132-135.

Ide, S., and H. Aochi (2005). Earthquakes as multiscale dynamic ruptures with heterogeneous fracture surface energy, J. Geophys. Res. 110, doi: 10.1029/2004JB003591.

Ide, S., and H. Aochi (2013). Historical seismicity and dynamic rupture process of the 2011 Tohoku-Oki earthquake, Tectonophysics 600, 1-13.

Kase, Y. (2010). Slip-length scaling law for strike-slip multiple segment earthquakes based on dynamic rupture simulations, Bull. Seismol. Soc. Am. 100, 473-481, doi: 10.1785/0120090090.

King, G., and J. Nábelek (1985). Role of fault bends in the initiation and termination of earthquake rupture, Science 228, 984-987.

Le Pichon, X., N. Chamot-Rooke, C. Rangin, and A. M. C. Sengör (2003). The North Anatolian fault in the Sea of Marmara, J. Geophys. Res. 108, doi: 10.1029/2002JB001862.

Mai, P. M., and G. C. Beroza (2002). A spatial random field model to characterize complexity in earthquake slip, J. Geophys. Res. 107, doi: 10.1029/2001JB000588.

Mena, B., L. A. Dalguer, and P. M. Mai (2012). Pseudodynamic source characterization for strike-slip faulting including stress heterogeneity and super-shear ruptures, Bull. Seismol. Soc. Am. 102, 1654-1680, doi: 10.1785/0120110111.

Oglesby, D. D., and P. M. Mai (2012). Fault geometry, rupture dynamics and ground motion from potential earthquakes on the North Anatolian fault under the Sea of Marmara, Geophys. J. Int. 188, 1071-1087.

Oglesby, D. D., S. M. Day, Y. G. Li, and J. E. Vidale (2003). The 1999 Hector Mine earthquake: The dynamics of a branched fault system, Bull. Seismol. Soc. Am. 93, 2459-2476.

Parsons, T., S. Toda, R. S. Stein, A. Barka, and J. H. Dieterich (2000). Heightened odds of large earthquakes near Istanbul: An interactionbased probability calculation, Science 288, 661-665.

Peyrat, S., R. Madariaga, and K. B. Olsen (2001). Dynamic modelling of the 1992 Landers earthquake, J. Geophys. Res. 106, 25,467-25,482. 


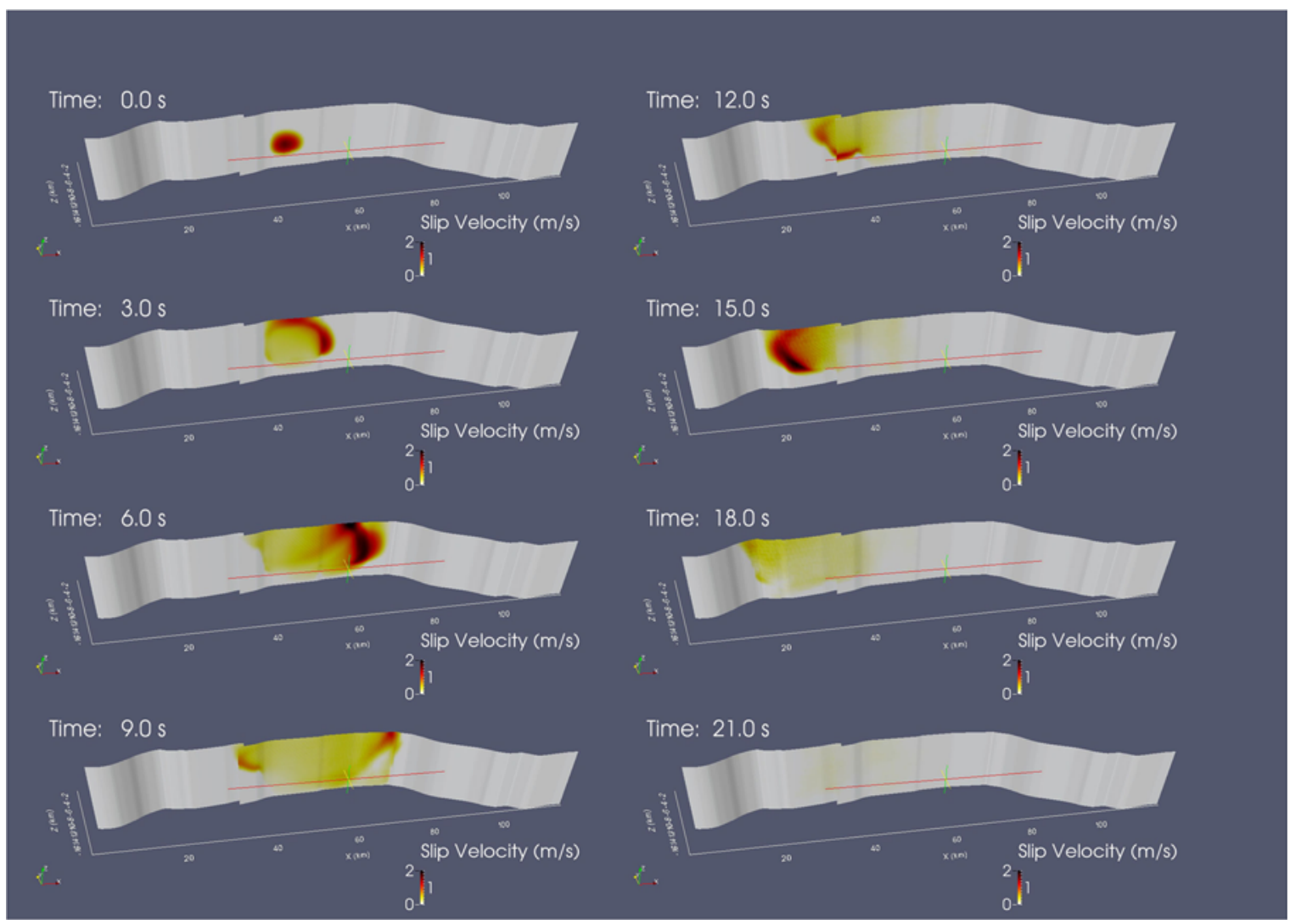

Figure A1. Snapshots of the dynamic-rupture simulation corresponding to the case with (a) the complex (LP) fault model, (b) $T=0.75$, and (c) the central location of the hypocenter (Hypo_C). The slip velocity is detailed with a $3 \mathrm{~s}$ time step. The regional PGV map associated with this scenario is shown in Figure 6c. The color version of this figure is available only in the electronic edition.

Pulido, N., A. Ojeda, K. Atakan, and T. Kubo (2004). Strong ground motion estimation in the Sea of Marmara region (Turkey) based on a scenario earthquake, Tectonophysics 391, 357-374.

Quin, H. (1990). Dynamic stress drop and rupture dynamics of the October 15, 1979 Imperial Valley, California, earthquake, Tectonophysics 175, 93-117.

Ruiz, S., and R. Madariaga (2013). Kinematic and dynamic inversion of the 2008 northern Iwate earthquake, Bull. Seismol. Soc. Am. 103, 694-708.

Sabetta, F., A. Lucantoni, H. H. Bungum, and J. J. Bommer (2005). Sensitivity of PSHA results to ground motion prediction relations and logic-tree weights, Soil Dynam. Earthq. Eng. 25, 317-329.

Schmedes, J., R. J. Archuleta, and D. Lavallée (2012). A kinematic rupture model generator incorporating spatial interdependency of earthquake source parameters, Geophys. J. Int. 192, 1116-1131, doi: 10.1093/gji/ ggs021.

Schmittbuhl, J., H. Karabulut, O. Lengliné, M. Bouchon, and the CINNET Team (2014). Creeping and locked segments along the main Marmara fault, European Geosciences Union General Assembly Conference Abstracts, Vol. 16, Vienna Austria, 27 April-2 May 2014, Abstract 12416.

Sibson, R. H. (1982). Fault zone models, heat flow, and the depth distribution of earthquakes in the continental crust of the United States, Bull. Seismol. Soc. Am. 72, 151-163.

Song, S. G., and L. A. Dalguer (2013). Importance of 1-point statistics in earthquake source modelling for ground motion simulation, Geophys. J. Int. 192, 1255-1270, doi: 10.1093/gji/ggs089.

Trugman, D. T., and E. M. Dunham (2014). A 2D pseudodynamic rupture model generator for earthquakes on geometrically complex faults, Bull. Seismol. Soc. Am. 104, 95-112, doi: 10.1785/0120130138.

Tryon, M. D., P. Henry, M. N. Çağatay, T. A. C. Zitter, L. Géli, L. Gasperini, P. Burnar, S. Bourlange, and C. Grall (2010). Pore fluid chemistry of the North Anatolian fault zone in the Sea of Marmara: A diversity of sources and processes, Geochem. Geophys. Geosyst. 11, doi: 10.1029/ 2010 GC003177.

Wesnousky, S. G. (2008). Displacement and geometrical characteristics of earthquake surface ruptures: Issues and implications for seismic-hazard analysis and the process of earthquake rupture, Bull. Seismol. Soc. Am. 98, no. 4, 1609-1632.

\section{Appendix}

In this appendix, we show snapshots of a dynamicrupture simulation along a geometrically complex fault (Fig. A1). This corresponds to the case with (a) the complex (LP) fault model, (b) $T=0.75 \mathrm{~s}$, and (c) the central location of the hypocenter (Hypo_C), namely with a probability of $5.2 \%$. Slip velocity is represented with a 3 s time step.

Risks and Prevention Direction, Bureau de Recherches Géologiques et Minières

3 Avenue Claude Guillemin, BP36009

Orléans Cedex 2, 45060

France

h.aochi@brgm.fr

thomas.ulrich@laposte.net

Manuscript received 22 September 2014; Published Online 5 May 2015 